\title{
Isotopic signature of tetravalent uranium mobilization by complexation or oxidation
}

\author{
YVONNE ROEBBERT ${ }^{1}$, CHRIS DANIEL ROSENDAHL $^{1}$, \\ ASHLEY BROWN ${ }^{2}$, AXEL SCHIPPERS ${ }^{3}$, RIZLAN \\ BERNIER-LATMANI ${ }^{2}$ AND STEFAN WEYER ${ }^{4}$ \\ ${ }^{1}$ Leibniz University Hannover, Institute for Mineralogy \\ ${ }^{2} \mathrm{EPFL}$ \\ ${ }^{3}$ Federal Institute for Geosciences and Natural Resources (BGR) \\ ${ }^{4}$ Wilhelm Leibniz Universität Hannover, Institut für Mineralogie \\ Presenting Author: y.roebbert@mineralogie.uni-hannover.de
}

Uranium (U) isotopes are suggested as a tool to monitor the success of a (bio)remediation method that relies on the reduction of mobile hexavalent $[\mathrm{U}(\mathrm{VI})]$ to more immobile tetravalent $\mathrm{U}$ [U(IV)] [1,2]. However, the subsurface stability of U(IV), typically present as solid-phase non-crystalline $U$, may be affected by reactions with ligands, oxidants or bacteria, that can result in $\mathrm{U}$ isotopic fractionation. Understanding these processes and their impact on $U$ isotope fractionation is important to correctly interpret field $U$ isotope signatures.

Here, we investigated two pathways of uranium mobilization, complexation and oxidation, and measured the associated $U$ isotope fractionation in laboratory batch experiments. First, a $\mathrm{U}(\mathrm{VI})$ isotope standard was reduced by Shewanella oneidensis MR-1 in a phosphate-containing medium (WLP) to produce noncrystalline U(IV) which was used as the starting material for all experiments [3]. Subsequently, U(IV) was mobilized in three different ways: 1) with organic ligands (EDTA, citrate, or bicarbonate), 2) by oxidation with $\mathrm{Fe}(\mathrm{III})$, or 3) with molecular oxygen at low $\mathrm{pH}$ in the presence of the bacterium Acidithiobacillus ferrooxidans. Aliquots collected at various time intervals were analyzed for their $U$ concentration and ${ }^{238} U /{ }^{235} U$ isotope ratios.

All ligands mobilized U(IV) effectively and enriched ${ }^{238} \mathrm{U}$ in the complexed fraction, resulting in $\delta^{238} \mathrm{U}$ values for aqueous $\mathrm{U}$ ranging between 0.2 and $0.6 \%$. Additionally, while the reaction with $\mathrm{Fe}(\mathrm{III})$ caused oxidative $\mathrm{U}$ mobilization, no $\mathrm{U}$ isotope fractionation was observed. For oxidation with At. ferrooxidans biomass, no significant $U$ isotope fractionation was observed either. The overall isotope fractionation was either very small or consisted of mutually cancelling contributions from individual steps. The latter may be indicated by the observation of high aqueous $\delta^{238} \mathrm{U}$ values $(\sim 0.8 \%$ ) in corresponding abiotic control experiments (without biomass), which may be the result of adsorption processes after oxidative $\mathrm{U}$ mobilization.

[1] Basu, A. et al., Environ. Sci. Technol. 2015, 49 (10), 5939 5947.

[2] Bopp, C. J. I. et al., Environ. Sci. Technol. 2010, 44 (15), 5927-5933.

[3] Stylo, M. et al., Environ. Sci. Technol. 2013, 47 (21), 12351-12358. 